\title{
Research Methods and Prospect of Dynamic Coupling Mechanical Properties of Weapons and Soft Ground
}

\author{
LiRong Zhang ${ }^{1, a}$, Jianxin Zhao ${ }^{2, b}$,Yongcai Chen ${ }^{3, c}$ \\ ${ }^{1,2,3}$ School of Ordnance Engineering College,Shijiazhuang 050000,China. \\ a648870741@qq.com
}

Keywords: Soft ground,Terramechanics,Research methods,Prospect

\begin{abstract}
Research on dynamic coupling mechanical properties between weaponry and soft ground is a frontier subject in the field of terramechanics. It mainly deals with the research of infantry weaponry, artillery weaponry, ammunition equipment, military vehicle equipment and ground and their interaction dynamics.By reviewing a large amount of data and research, this paper summarizes the present research situation, research methods in this field, and points out the problems to be solved in this field and the development trend in the future according to the actual situation in China.It is of great reference value and guidance significance for the further study of the interaction between weaponry and soft ground.
\end{abstract}

\section{Introduction}

Research on the interaction between weapon and soft ground belongs to machine / tool-soft ground dynamic coupling mechanics, which is the foremost subject in the terramechanics field.In this subject, it is mainly to study the mechanical relation between the vehicle and the ground, where "vehicle" mainly refers to off-road vehicles that can be laid on non-artificial road driving vehicles,and "ground" refers to the geometry of the rock and soil and its composition, which provide the supporting capacity and the ability to attach to the vehicle.The soft soil is a natural water content, high compressibility, low strength, soft plastic state of the cohesive soil[1].The research on machine / tool-soft ground dynamic coupling mechanics is recognized by J.Y. Wong, the most authoritative scholar in the field of terramechanics, but the whole research is in its infancy.The reasons for this situation is not that the current theoretical and technical reserves can not meet the research needs,but based on the semi empirical and semi analytical method, the theory of ground mechanics has developed for many years.In this time,a large number of physical experiments / experimental data to the theoretical model has been empirical correction,which to a certain extent alleviates the inherent defects of the ground mechanics theory and method of machine / tool - soft ground coupling effect on static / quasi-static description.However, the theoretical basis for the study of the interaction between the machine / tool and the soft ground based on the dynamic load is still not perfect, which is the main direction of the future development of the subject.Based on a lot of literatures and in-depth research, this paper summarizes the current research situation, research methods in this field at home and abroad.Combined with the consideration of the actual use of military weapons and equipment, the key issues in this field research need to solve have been proposed.

\section{Research Method}

After years of development, many researchers have taken different approaches to study the interaction of machine / tool and soft ground,to sum up can be divided into five kinds.

Pure Empirical Method.The pure empirical method is to identify the soil properties on the basis of observation and measurement, and then to test the machine / tool on various types of soil.Finally, the relationship between soil properties and machine / tool performance is deduced based on the experimental results of different groups.The most typical representation of the pure empirical 
method is the Cone Index Method (WES method) of the US Army Corps of Engineers waterway test station.However, this method has great limitations, which is only valid for test vehicles and similar vehicles, and for other vehicles can not accurately predict its trafficability characteristic.

Semi - Empirical Method.The semi-empirical method is currently the most widely used method.The mechanics analysis of the machine / tool interaction with the ground is carried out, and the approximate formula of the wheel - soil interaction is established on the basis of appropriate experiment.The semi - empirical formula can be used to quantitatively describe the physical properties related to the vehicle and provide a theoretical basis for the prediction of the wheel 's ground mechanical properties. The most representative semi-empirical method is M.G.Bekker's method.However, this method is based on experiments and lacks a rigorous theoretical basis, which can not fundamentally explain the internal relationship between vehicles and the ground,When the test conditions are different, the model results and test results are often very different.

Model Test and Dimensional Analysis Method.The model test and the dimension analysis method are used to analyze the relationship between the vehicle and the soil by using the dimension analysis theory to test the model with a similar proportion of the prototype.In 1957, Professor Chen Bingcong[2] of Jilin University of Technology presided over the establishment of experimental soil tank model. Based on the similarity theory and model analysis method, the working process of the vehicle running mechanism was simulated in the indoor soil trough, which provided a kind of intuitive and effective method for the evaluation of walking mechanism on trafficability characteristic.However, the model test and the dimension analysis method are not applicable to the microscopic local phenomena in the experiment, and need to be tested by the physical model.

Basic Theory Research Method.The basic theory research method is to apply soil mechanics theory, elastoplasticity theory and constitutive relation theory to study the interaction between soil and machine / tool.

Numerical Simulation Method.Since the 1960s, with the development of computer technology, finite element method, boundary element method, discrete element method and other numerical simulation methods have been applied to terramechanics. The numerical simulation method has a rigorous theoretical foundation and is versatile. With the deepening of the research content, the research scope and practical value will be further improved. This method will be widely used in terramechanics.

\section{Research Status}

Research on dynamic coupling mechanical properties between weapon and soft ground is the front subject of terramechanics.Terramechanics is a compound word for "ground" and "mechanics",which first appeared in the "off-road driving" published by Bekker in 1960.The International Journal of Terrestrial Machinery Systems used it as the Journal of Terramechanics, which was first published in 1962, and has since gained international recognition as a proper term for the mechanical problems of machine-to-ground interaction.Terramechanics research is divided into two aspects, namely ,the vehicle walking mechanism and the soil function mechanics and the interaction between the soil working machinery and soil (cut, turn, broken soil, etc.) mechanics[3].

Throughout the Army weapons and equipment system, a large number of equipments of infantry, artillery, air defense force, armored force,engineering force ,etc in the process of coupling with the soft ground in the military field is very common phenomenon.However, due to the complexity of the response characteristics of the soft ground under load, for a long time, the military engineering field has less research on the complex mechanical process of the weapon equipment and the soft ground coupling, and the design theory in the process of the weapon equipment research and development has many multiple simplifying assumptions.At present, the research on the interaction between weapon and soft ground belongs to machine / tool-soft ground dynamic coupling mechanics, which can provide a lot of reference for it.In the late World War II, the US military found that soil conditions would restrict the action of tanks, some of the immeasurable soil conditions and changes often made the development of operational plans destroyed.Therefore, the US waterway test station proposed the use of cone penetration meter to 
detect the soil parameters of a combat area (cone index I), and then as a basis for judging the chariot passing capacity.This method is simple, suitable for field measurements, and is still widely used.But it is based on a lot of the measured data, the results of the judgment belong to the category of empirical methods,and does not have universal significance[4].The influence of the penetration rate on the dynamic response characteristics of the two soft ground materials in loam and sand was studied by M.Grahn et al., Institute of Automotive Research, German Federal University of Germany (IKK) during the period of 1990 1995.In addition, the effect of the traveling speed on the stress distribution in the wheel-soft ground contact interface and the wheel subsidence and rolling resistance on the sandy loam is studied[5].In addition, for wheeled vehicles, the effect of the traveling speed on the stress distribution in the wheel-soft ground contact interface and the wheel subsidence and rolling resistance on the sandy loam was studied[6].Researchers at the Engineer Research and Development Center/Army Cold Regions Research \& Engineering Laboratory (ERDC / CRREL) conducted an experimental study on the effects of wheel speed on rolling resistance on the sand at the NASA Langley Research Center experimental site.The results show that there is very little agreement between the rolling resistance analytical model and the experimental results published in the literature, and some research results are even contradictory to the experimental results, which shows that the research on the effect of wheel speed on rolling resistance is far from deep degree[7].Researchers at the Technion-Israel Institute of Technology investigated the effect of speed on the traction performance of rigid wheels on soft ground,and by introducing the velocity correction term in the relationship of pressure-subsidence and shear press-shear displacement accounted for the influence of the deformation rate of soft ground material on the response characteristics of the proposed model[8].In the aspect that a nonlinear dynamical model describing the dynamic characteristics of the soft ground coupling system, which is a component of the load application mechanism of the weapon equipment,and the corresponding force cell model were developed,ZhengDong Ma and N.C.Perkins of the University of Michigan studied the mathematic model of the crawler-load wheel-soft ground interaction, and presented the super-cell model of the load-wheel-track-soft ground quasi-static coupling system mechanics characteristics, which is a dynamic model for the simulation of the whole vehicle dynamics of the tracked vehicle.The model can describe the characteristics of crawler tension variation, track elongation and large deformation of track due to uneven distribution of normal stress and shear stress under the track.

\section{Problems and Prospects in Research}

Combined with the current research situation, there is still a long way to go in the military field for the study of terramechanics:

a)Due to the complexity of the soil environment, considering the soil type, structure, water content and the loading mode and loading speed of the machine / tool to the soil,it is difficult to find the exact constitutive relationship of the soil for the application of computational mechanics to the terramechanics.Therefore, it is necessary to study the accurate constitutive relation of soil and to select the appropriate research method.

b)In the field of military engineering, more attention is focused on the dynamic response of soft ground under dynamic loading, such as impact load, blast load and vibration load.However, most of the terramechanics theories proposed by Bekker and ZuYong Huang are based on static / quasi-static conditions, and there is not a mature theoretical system for the dynamic response of dynamic load.Secondly, in the field of military engineering it should also consider the practical problems of engineering, such as in the soft conditions of the accuracy of firearms, ammunition damage performance and vehicle mobility performance.These are in-depth study of the future issues.

c)With the development of numerical analysis methods, there have been many powerful computer numerical analysis software, in some software also has a special soil analysis module, but most of the modules are based on static / quasi-static conditions, the dynamic condition load module also need to be further developed by the researchers. 
d) In addition to computer simulation technology, virtual and real technology, robotics and its control theory, bionics and other technologies and theories can also be applied to machines / tools and soft ground research.

\section{References}

[1]Information on http://www.baike.com/wiki.

[2]Bingcong Chen.Ground - Vehicle System Mechanics[M].Beijing:Agricultural Machinery Press,1981.

[3]Bekker M.G.Ground - Vehicle System Introduction[M].Beijing:Agricultural Machinery Press,1978.

[4]J.Y.Wong.Terramechanics and Off-Road Vehicles[M].New York:ELSEVIER SCIENCE PUBLISHING COMPANY INC,1989.

[5]Grahn M. Investigation of the influence of penetration velocity on the pressure/sinkage relationship, in 9th Int Conf of the ISTVS. 1987: Barcelona.

[6]Grahn M.,Prediction of sinkage and rolling resistance for off-the-road vehicles considering penetration velocity, in 10th Int Conf of the ISTVS. 1990: Kobe.

[7]Barry Coutermarsh.Velocity effect of vehicle rolling resistance in sand[J].Journal of Terramechanics,2007,44:275-291.

[8]I.Shmulevich,U.Mussel,D.Wolf.The effect of velocity on rigid wheel performance[J].Journal of Terramechanics,1998,35:189-207. 